\title{
Effects of COVID-19 Pandemic on Mental Health Status of COVID-positive Pregnant Women in a COVID Care Center: A Prospective Observational Study
}

\author{
Deepali P Kale ${ }^{1}$, Trupti K Nadkarni ${ }^{2}$, Amol P Pawar ${ }^{3}$, Pooja M Shah ${ }^{4}$, Vandana Bansal ${ }^{5}$, Mehrnoosh Jassawala ${ }^{6}$, \\ Minnie Bodhanwala ${ }^{7}$
}

\begin{abstract}
Background:The global pandemic of the novel coronavirus disease 2019 (COVID-19) has created a public health emergency straining the entire human race. The population of antenatal and postnatal women is subjected to additional anxiety and psychological stress due to issues related to the pandemic like the public health measures, such as quarantine, and anxiety about the health of the fetus.

Aim: To study the prevalence of depression and anxiety in antenatal and postnatal women during the COVID-19 pandemic.

Materials and methods: We have screened 300 women in a COVID-19 care center for psychological depression and anxiety. The Edinburgh postpartum depression scale (EPDS) and also a self-reported questionnaire with COVID-specific anxiety questionnaire with eight items related to the COVID -9 pandemic were answered in graded response scale from 1 to 5 . The clinical records identifying high-risk factors along with EPDS score and anxiety response were analyzed. EPDS greater than 13 was suggestive of probable depression. Anxiety questions were analyzed according to the percentage of questions that have been marked as 'much' and 'very much' responses.

Results: Among 300 women, the prevalence of depression was $43.3 \%$. The anxiety question marked by $39 \%$ of women was about worries of the health of fetus graded as "very much" followed by that regarding the worries about delivery marked by $25.3 \%$ of women as very much.

Conclusion: The increased psychological distress among pregnant women irrespective of COVID-19 status is significant. The preventive mental health strategies should be integrated with antenatal and postnatal care of women during the pandemic.

Keywords: Anxiety, COVID-19, Depression, Edinburgh postpartum depression scale, Pandemic, Postpartum, Pregnancy.

Journal of South Asian Federation of Obstetrics and Gynaecology (2021): 10.5005/jp-journals-10006-1904
\end{abstract}

\section{INTRODUCTION}

The global outbreak of novel coronavirus disease 2019 (COVID-19) has created a public health emergency worldwide since December 2019. ${ }^{1}$ The threatening viral outbreak with enormous uncertainty spiking new information updates every minute puts an additional burden on the mental well-being of pregnant women. ${ }^{2}$

The pregnant state itself is prone to mental health problems like depression and anxiety with prevalence being $12 \%$ for depression and $13 \%$ for anxiety. The recent National Institute for Health and Care Excellence (NICE*) guidelines on antenatal and postnatal mental health highlighted the necessity of screening for the mental health issues of pregnant women. ${ }^{3}$

The prevalence of depression studied in the World Health Organization (WHO*) recent systematic review is $22 \%$, which is significantly high compared to the developed nations of 10 to $15 \%$ and represents the tip of the iceberg. ${ }^{4}$ The depression and anxiety in antenatal and postnatal women have been linked to the negative effects of mother-infant bonding and adverse effects on the development of the offspring in the form of learning disabilities. ${ }^{5-8}$

Recent meta-analyses by Dennis et al. have estimated the prevalence of anxiety in pregnancy ranging from 8.5 to $15.2 \%$ prenatally, and $9.9 \%$ postnatally. ${ }^{9}$

The necessity of mental well-being during COVID-19* pandemic has been highlighted by $\mathrm{WHO}^{*}$ and Centers for Disease Control and Prevention (CDC*). WHO has further stressed the importance of the integration of mental health needs into public health response. ${ }^{10}$
${ }^{1-7}$ Department of Obstetrics and Gynecology, Nowrosjee Wadia Maternity Hospital, Mumbai, Maharashtra, India

Corresponding Author: Trupti K Nadkarni, Department of Obstetrics and Gynecology, Nowrosjee Wadia Maternity Hospital, Mumbai, Maharashtra, India, Phone: +91 09503614668, e-mail:truptidp@ gmail.com

How to cite this article: Kale DP, Nadkarni TK, Pawar AP, et al. Effects of COVID-19 Pandemic on Mental Health Status of COVID-positive Pregnant Women in a COVID Care Center: A Prospective Observational Study. J South Asian Feder Obst Gynae 2021;13(3):167-173.

Source of support: Nil

Conflict of interest: None

The most commonly used measure to screen for a major depressive episode (MDE)* is Edinburgh postpartum depression scale (EPDS)*, a well-established, easy, and validated scale used globally. EPDS* evalautes the women's mental status for the past 7 days $\&$ has been validated to screen depression in antenatal and postnatal period. ${ }^{11-13}$

EPDS has high sensitivity and specificity for the diagnosis of postpartum depression. The English language version has an optimal threshold for screening postnatal depression with a cutoff score of more than 13 out of 30 , which had a sensitivity of $86 \%$ and a specificity of $78 \% .^{11}$

Furthermore, many studies demonstrated that nearly $80 \%$ of depressive symptoms (EPDS score of 13 or higher) occur during pregnancy, rather than postpartum.

( ) Jaypee Brothers Medical Publishers. 2021 Open Access This article is distributed under the terms of the Creative Commons Attribution 4.0 International License (https://creativecommons.org/licenses/by-nc/4.0/), which permits unrestricted use, distribution, and non-commercial reproduction in any medium, provided you give appropriate credit to the original author(s) and the source, provide a link to the Creative Commons license, and indicate if changes were made. The Creative Commons Public Domain Dedication waiver (http://creativecommons.org/publicdomain/zero/1.0/) applies to the data made available in this article, unless otherwise stated. 
An eight items questionnaire checking the women's COVID-19related anxiety as depicted in their perception of several aspects of the situation has been studied by Taubman-Ben-Ari et al. ${ }^{14}$ The women were asked about their perception of the pandemic and its effect on pregnancy care in terms of anxiety. Responses were marked on a scale from 1 (very little) to 5 (very much). ${ }^{14}$

\section{Materials and Methods}

This is a prospective observational study done over 6 months from August 2020 to January 2021 at Nowrosjee Wadia Maternity Hospital, Mumbai. In our COVID-19 care center, registered antenatal and postnatal women, as well as those who have been referred to our center with COVID-19-positive status, are cared. We have screened 300 antenatal and postnatal women for depression and anxiety. One hundred and fifty participants were COVID-19-positive status, and 150 participants were COVID-19-negative status, who have been selected as population matched controls from the same hospital.

The study population was recruited after their consent for participation in the study and to view the clinical records of their antenatal and postnatal period. The antenatal and postnatal participants were given the EPDS of 10 questionnaire scale with points up to 30 . The EPDS scale in our study was used in Khapre, ${ }^{15}$ which is a preferred local language by most of the participants, and EPDS was also in Hindi and English languages. EPDS has been a well-approved scale applied in pregnancy with two items, anxiety pro and the rest with depression. The three components within the EPDS consist of first one (item 1,2 \& 8) depicts depression, second one (item 3,4,5) depicts anxiety and third component (item 10) depicts thoughts of self-harm. ${ }^{16}$

Those participants whose EPDS score was greater than 13 were offered one-to-one counseling in person and also telephonically on a virtual platform. They have also been referred to a psychiatrist for virtual and telephonic conversation.

The case record forms included demographic variables, obstetric and medical history along with the personal and family history of psychiatric illness, antenatal stress factors like current pregnancy complications in mother and complications in fetus, as well as COVID 19 specific factors like the affection of family members, and antenatal and postnatal care experience during the pandemic period of limited resources.
A questionnaire specific to the COVID-19 situation was also given to them for self-score. ${ }^{14}$

This questionnaire included eight items related to the participant's COVID-19-related anxiety, as reflected in their perception of several aspects of the pandemic situation. The responses were marked from 1 (very little) to 5 (very much). ${ }^{14}$ The responses were analyzed in percentages.

\section{Ethical Considerations}

The study was approved (IEC-NWMH Project No. IEC- NWMH/ AP/2020/049) by the Institutional Ethics Committee and has been conducted as per Helsinki's code of ethics.

\section{Inclusion Criteria}

- Antenatal patients and postnatal women with COVID-19-positive and negative status

- Women who consented to the study participation.

\section{Exclusion Criteria}

- Patients admitted for medical termination of pregnancy at first and second trimesters and ectopic pregnancy.

- Patients with a history of psychiatric illness.

\section{Statistical Analysis}

Outcome measures were evaluated in percentages and proportions. Data were entered in Microsoft Excel sheets. Qualitative and categorical variables were analyzed using Chi-square test and Fischer's exact test. A $p$-value of $<0.05$ was accepted as statistically significant. For the presentation of variables, the mean and standard deviation was used. The data were analyzed with SPSS software version 25.

\section{Results}

A total of 300 participants have been enrolled in our study, among which 150 participants were tested COVID-19 positive and 150 participants were COVID-19 negative.

The EPDS cutoff of score $\geq 13$ was suggested as probable depression.

The prevalence of depression observed in our study is $43.3 \%$. The prevalence among the COVID-positive women was $47.7 \%$, and COVID-negative women was $52.3 \%$. There was no statistically significant difference between the two groups. ( $p$-value, 0.485 ) (Table 1).

Table 1: COVID-19 status $^{*}$ depression+ cross-tabulation (cutoff $>13$ )

\begin{tabular}{|c|c|c|c|c|c|}
\hline & & & Depress & ion+ & \\
\hline & & & Not depressed & Depressed & Total \\
\hline COVID-19 status & Positive & Count & 88 & 62 & 150 \\
\hline & & Expected count & 85.0 & 65.0 & 150.0 \\
\hline & & $\%$ within COVID-19 status & $58.7 \%$ & $41.3 \%$ & $100.0 \%$ \\
\hline & & $\%$ within depression+ & $51.8 \%$ & $47.7 \%$ & $50.0 \%$ \\
\hline & Negative & Count & 82 & 68 & 150 \\
\hline & & Expected count & 85.0 & 65.0 & 150.0 \\
\hline & & $\%$ within COVID-19 status & $54.7 \%$ & $45.3 \%$ & $100.0 \%$ \\
\hline & & $\%$ within depression+ & $48.2 \%$ & $52.3 \%$ & $50.0 \%$ \\
\hline Total & & Count & 170 & 130 & 300 \\
\hline & & Expected count & 170.0 & 130.0 & 300.0 \\
\hline & & $\%$ within COVID-19 status & $56.7 \%$ & $43.3 \%$ & $100.0 \%$ \\
\hline & & $\%$ within depression+ & $100.0 \%$ & $100.0 \%$ & $100.0 \%$ \\
\hline
\end{tabular}


The mean age of the participants was 29.4 and 28.5 years in COVID-positive and negative women, respectively.

Overall, $52.7 \%$ of women were from families with an average family income of 50,000 per month. In this income category, the prevalence of depression was $48.6 \%$ in COVID-19-positive and $51.4 \%$ in COVID-19-negative groups.

In the education group of graduate women, $53.7 \%(n=88)$ of women were COVID-19 positive, out of which 51.9\% $(n=40)$ were depressed. Out of $46.7 \%(n=77)$ of COVID-negative women, $46.3 \%$ $(n=37)$ were depressed.

In our study, $39 \%(n=117)$ of women were from the government-specified red containment zones. ${ }^{17}$ In this study, $62.66 \%(n=206)$ of women were with family members of $2-5$. Out of 300 women, $53 \%$ ( $n=159)$ of women were from joint families. Out of 300 women, $4 \%$ of women $(n=12)$ had family members affected with COVID-19 (Table 2).

Among COVID-positive antenatal ( $N=98$ ) women, $62.9 \%$ ( $n=39$ ) were depressed, and among postnatal $(N=52), 37.1 \%$ ( $n=23)$ were depressed (Table 3).

Trimester-wise, $89.79 \%(n=88)$ of antenatal women in the COVID-19-positive group were in their third trimester, and $86.20 \%$ ( $n=50)$ from COVID-19-negative group were in their third trimester $(n=50)$ (Table 4).

Among COVID-negative antenatal ( $N=58$ ) women, $42.6 \%$ $(n=29)$ were depressed and $52.7 \%(n=39)$ in postnatal $(N=92)$ (Table 3).

The total percentage of primigravidae in our study was $60 \%$ ( $n=180)$ followed by a second gravida of $24.3 \%(n=73)$.

Regarding the COVID-19 preventive measures, 134 women from COVID-19-positive group had awareness about hand hygiene, social distancing, and use of masks, whereas 16 women had inconsistent awareness about these measures. And 137 women from COVID-19negative group were aware of all three preventive measures and 13 had inconsistent awareness. A total of 271 (90.33\%) out of 300 women were aware of preventive measures of COVID-19.

\section{Anxiety Scale Analysis (Table 5) ${ }^{14}$}

In the anxiety questionnaire, the most marked response worded "Very much" was observed regarding the anxiety of the health of the fetus (39\%) $(p=0.05)$. This was followed by the response worded "Much" (25.7\%) ( $p=0.05)$.

This was followed by anxiety about the delivery (25.3\%) $(p=0.05)$, and anxiety questions that had a significant $p$ value for anxiety over being infected themselves $(p<0.05)$, use of public transport $(p<0.05)$, and going for an antenatal checkup $(p<0.05)$ were significant.

\section{Discussion}

The effects of the COVID-19 pandemic on mental well-being are likely to be significant and have a long-term impact on the global population. $^{10}$

The Web-based survey done by Ceulemans et al. showed that the antenatal and postnatal women are emotionally labile during the restrictions in the lockdown. Our study highlighted the same facts that the isolation and restrictions laid down in the pandemic have caused pregnant women to submerge themselves into the unexpressed hidden depression and anxiety. ${ }^{18}$

The prevalence of perinatal depression (EPDS $>13$ ) in our study, that is, $43.3 \%$, is almost double the perinatal depression in developing countries during the non-pandemic time. ${ }^{4}$

Durankus et al. and Lebel et al. have shown the increased prevalence of depression as 35.4 and as $37 \%$, respectively. ${ }^{19,20}$

The association between COVID-19-positive and negative status was not significant for anxiety and depression. This means the pandemic has overall affection on the mental well-being of the pregnant population. $^{21}$

Studies done by $\mathrm{Ng}$ et al. during the previous pandemic have shown that concerns for the financial stress due to unemployment had caused economic crisis and explain the reason for middle- and low-income group women being at increased risk. The middleand low-income group women who have to leave home to work full-time may have increased concern for infection and vertical transmission and thus increased the risk for depression. ${ }^{22}$

This was observed in our study that in the middle-income group women (150), 50\% were depressed.

The educated group had more depression in our study due to access to the Internet and vast amount of uncertain information. This is comparable to the study done by Ceulemans et al. and Jiang et al. ${ }^{21,23}$

As per the Municipal Corporation norms, 117 women in our study, that is, 39\%, were from the red zone (Table 2) where lockdown restrictions were being applied at a stringent level by the government. ${ }^{17}$

Family support usually lowers the risk of depression; however, during the lockdown and isolation period, the women being

Table 2: Demographic variables plotted against COVID-19 status

\begin{tabular}{|c|c|c|c|c|c|}
\hline & & \multicolumn{2}{|c|}{ COVID-19 positive $(N=150)$} & \multicolumn{2}{|c|}{ COVID-19 negative $(N=150)$} \\
\hline & & $n$ & $\%$ & $N$ & $\%$ \\
\hline \multirow[t]{3}{*}{ Age } & Mean & 29.49 & & 28.53 & \\
\hline & SD & 4.93 & & 4.81 & \\
\hline & SEM & 0.359 & & 0.393 & \\
\hline \multirow[t]{3}{*}{ Zone } & Red & 58 & 38.66 & 59 & 39.33 \\
\hline & Orange & 50 & 33.33 & 50 & 33.33 \\
\hline & Green & 42 & 28 & 41 & 27.33 \\
\hline \multirow[t]{3}{*}{ Number of family members } & $>5$ & 27 & 18 & 37 & 24.66 \\
\hline & $2-5$ & 112 & 74.66 & 94 & 62.66 \\
\hline & 2 & 11 & 7.33 & 19 & 12.66 \\
\hline \multirow[t]{2}{*}{ Type of family } & Joint & 75 & 50 & 84 & 56 \\
\hline & Nuclear & 74 & 49.33 & 66 & 44 \\
\hline \multirow[t]{2}{*}{ Family member affected } & Yes & 5 & 3.33 & 7 & 4.66 \\
\hline & No & 145 & 96.66 & 143 & 95.33 \\
\hline
\end{tabular}


Table 3: ANC, PNC, and EPDS

\begin{tabular}{|c|c|c|c|c|c|c|}
\hline \multirow[b]{2}{*}{ COVID-19 status } & & & & \multicolumn{2}{|c|}{ Depression+ } & \multirow[b]{2}{*}{ Total } \\
\hline & & & & Not depressed & Depressed & \\
\hline \multirow[t]{9}{*}{ Positive } & ANC or PNC & ANC & Count & 59 & 39 & 98 \\
\hline & & & $\%$ within ANC or PNC & $60.2 \%$ & $39.8 \%$ & $100.0 \%$ \\
\hline & & & $\%$ within depression+ & $67.0 \%$ & $62.9 \%$ & $65.3 \%$ \\
\hline & & PNC & Count & 29 & 23 & 52 \\
\hline & & & $\%$ within ANC or PNC & $55.8 \%$ & $44.2 \%$ & $100.0 \%$ \\
\hline & & & $\%$ within depression+ & $33.0 \%$ & $37.1 \%$ & $34.7 \%$ \\
\hline & Total & & Count & 88 & 62 & 150 \\
\hline & & & $\%$ within ANC or PNC & $58.7 \%$ & $41.3 \%$ & $100.0 \%$ \\
\hline & & & $\%$ within depression+ & $100.0 \%$ & $100.0 \%$ & $100.0 \%$ \\
\hline \multirow[t]{9}{*}{ Negative } & ANC or PNC & ANC & Count & 29 & 29 & 58 \\
\hline & & & $\%$ within ANC or PNC & $50.0 \%$ & $50.0 \%$ & $100.0 \%$ \\
\hline & & & $\%$ within depression+ & $35.4 \%$ & $42.6 \%$ & $38.7 \%$ \\
\hline & & PNC & Count & 53 & 39 & 92 \\
\hline & & & $\%$ within ANC or PNC & $57.6 \%$ & $42.4 \%$ & $100.0 \%$ \\
\hline & & & $\%$ within depression+ & $64.6 \%$ & $57.4 \%$ & $61.3 \%$ \\
\hline & Total & & Count & 82 & 68 & 150 \\
\hline & & & $\%$ within ANC or PNC & $54.7 \%$ & $45.3 \%$ & $100.0 \%$ \\
\hline & & & $\%$ within depression+ & $100.0 \%$ & $100.0 \%$ & $100.0 \%$ \\
\hline \multirow[t]{9}{*}{ Total } & ANC or PNC & ANC & Count & 88 & 68 & 156 \\
\hline & & & $\%$ within ANC or PNC & $56.4 \%$ & $43.6 \%$ & $100.0 \%$ \\
\hline & & & $\%$ within depression+ & $51.8 \%$ & $52.3 \%$ & $52.0 \%$ \\
\hline & & PNC & Count & 82 & 62 & 144 \\
\hline & & & $\%$ within ANC or PNC & $56.9 \%$ & $43.1 \%$ & $100.0 \%$ \\
\hline & & & $\%$ within depression+ & $48.2 \%$ & $47.7 \%$ & $48.0 \%$ \\
\hline & Total & & Count & 170 & 130 & 300 \\
\hline & & & $\%$ within ANC or PNC & $56.7 \%$ & $43.3 \%$ & $100.0 \%$ \\
\hline & & & $\%$ within depression+ & $100.0 \%$ & $100.0 \%$ & $100.0 \%$ \\
\hline
\end{tabular}

ANC, antenatal care; PNC, postnatal care.

separated from their families could be one of the contributing factors for more risk of depression and anxiety (Table 2).

A study by Jiang et al. assessed the knowledge and awareness of preventive measures of COVID-19 and found it low. The awareness and use of COVID-19 preventive measures like hand hygiene, use of masks, and social distancing in our study were $90.33 \%$. The study population was from an educated group and had access to social media and the Internet. ${ }^{23}$

The higher number of women who had antenatal registration in the third trimester shows the fear of being out of their houses to even seek basic antenatal care in earlier gestation. This is comparable to a study done by Ceulemans et al. ${ }^{21}$

The reduced number of antenatal visits (Table 4 ) in our study was 3 to 6 , which was less than the usual booked antenatal women as per the NICE guideline on antenatal care. ${ }^{24}$

This reveals the fact about the overall social restrictions imposed on the population and also the inherent stress of being in public places (Table 5). ${ }^{23,25}$

The new mothers are at higher risk of perinatal depression and anxiety, which is in concurrence with our study, suggesting that women who are naïve regarding the transition to pregnancy, labor, and postpartum time have unmet needs of support during this time. COVID-19 pandemic is an add on stressor on this first mothers. ${ }^{26,27}$

The anxiety scale adopted from Taubman-Ben-Ari et al., which had incorporated eight COVID-19-related questionnaires, has shown that concerns over the health of the fetus $(p=0.05)$ followed by concerns over the delivery $(p=0.05)$ had been marked as very much on the response scale (Table 5). This highlights the anxiety of the women over the risk of transmission of COVID-19 infection to the fetus in utero or after birth. ${ }^{14}$ This was also observed in a study done by Ravaldi et al. ${ }^{28}$

The anxiety over being infected themselves $(p<0.05)$, use of public transport $(p<0.05)$, and going for an antenatal checkup $(p<0.05)$ were significant. The containment restrictions and the transmission mode of the infective agent have led to anxiety over those factors.

Our present data revealed an increase in the proportion of women with thoughts of self-harm, which could potentially result in death and injury indirectly caused by this COVID-19 outbreak. In our study during the EPDS screening, eight patients have marked item 10, which is a cause for concern, as item 10 in EPDS involves 


\begin{tabular}{|c|c|c|c|c|c|}
\hline \multirow[b]{2}{*}{ ANC } & & \multicolumn{2}{|c|}{$\begin{array}{l}\text { COVID-19 positive } \\
N=150\end{array}$} & \multicolumn{2}{|c|}{$\begin{array}{l}\text { COVID-19 negative } \\
N=150\end{array}$} \\
\hline & & $n=98$ & $\%$ & $n=58$ & $\%$ \\
\hline \multirow[t]{3}{*}{ Trimester } & 1 & 3 & 3.6 & 0 & 0 \\
\hline & 2 & 7 & 7.14 & 8 & 13.7 \\
\hline & 3 & 88 & 89.79 & 50 & 86.20 \\
\hline \multirow[t]{2}{*}{ Booked/unbooked } & Booked & 129 & 86 & 123 & 82 \\
\hline & Unbooked & 21 & 14 & 27 & 18 \\
\hline \multirow[t]{3}{*}{ Number of ANC visits } & $<3$ & 26 & 17.33 & 28 & 18.66 \\
\hline & $3-6$ & 80 & 53.33 & 81 & 54 \\
\hline & $>6$ & 43 & 28.66 & 41 & 27.33 \\
\hline \multirow[t]{2}{*}{ High-risk factors } & Present & 43 & 28.66 & 65 & 43.33 \\
\hline & Absent & 107 & 71.33 & 85 & 56.66 \\
\hline \multirow[t]{2}{*}{ ANC experience } & Good & 108 & 72 & 130 & 86.66 \\
\hline & Not good & 42 & 28 & 20 & 13.33 \\
\hline PNC & & $n=52$ & & $n=92$ & \\
\hline \multirow[t]{2}{*}{ Mode of delivery } & Vaginal delivery & 31 & 59.61 & 52 & 56.52 \\
\hline & Cesarean section & 21 & 40.38 & 40 & 43.7 \\
\hline \multirow[t]{3}{*}{ Baby isolation } & Yes & 6 & & 0 & \\
\hline & No & 45 & & 92 & \\
\hline & IUFD & 1 & & 0 & \\
\hline \multirow[t]{3}{*}{ Lactation } & Comfortable & 43 & & 83 & \\
\hline & Uncomfortable & 8 & & 9 & \\
\hline & Suppression & 1 & & 0 & \\
\hline \multirow[t]{2}{*}{ PNC experience } & Good & 40 & & 130 & \\
\hline & Not good & 12 & & 20 & \\
\hline
\end{tabular}

Table 5: Anxiety scale analysis

\begin{tabular}{|c|c|c|c|c|}
\hline \multirow[b]{2}{*}{ Anxiety over } & \multicolumn{3}{|c|}{$(N=300)$} & \multirow[b]{2}{*}{ Chi-square tests } \\
\hline & Response & $N$ & $\%$ & \\
\hline \multirow[t]{5}{*}{ Economic damage } & Very little & 70 & 23.3 & \multirow[t]{5}{*}{$p$-value $=0.000$} \\
\hline & Little & 90 & 30.0 & \\
\hline & Moderately & 80 & 26.7 & \\
\hline & Much & 38 & 12.7 & \\
\hline & Very much & 22 & 7.3 & \\
\hline \multirow[t]{5}{*}{ Being infected by COVID-19 } & Very little & 117 & 39.0 & \multirow[t]{5}{*}{$p$-value $=0.041$} \\
\hline & Little & 65 & 21.7 & \\
\hline & Moderately & 66 & 22.0 & \\
\hline & Much & 32 & 10.7 & \\
\hline & Very much & 20 & 6.7 & \\
\hline \multirow[t]{5}{*}{ Family member affected by COVID-19 } & Very little & 118 & 39.3 & \multirow[t]{5}{*}{$p$-value $=0.144$} \\
\hline & Little & 55 & 18.3 & \\
\hline & Moderately & 66 & 22.0 & \\
\hline & Much & 38 & 12.7 & \\
\hline & Very much & 23 & 7.7 & \\
\hline \multirow[t]{5}{*}{ Being in public places } & Very little & 98 & 32.7 & \multirow[t]{5}{*}{$p$-value $=0.01$} \\
\hline & Little & 85 & 28.3 & \\
\hline & Moderately & 51 & 17.0 & \\
\hline & Much & 39 & 13.0 & \\
\hline & Very much & 27 & 9.0 & \\
\hline \multirow[t]{5}{*}{ Using public transport } & Very little & 94 & 31.3 & \multirow[t]{5}{*}{$p$-value $=0.03$} \\
\hline & Little & 56 & 18.7 & \\
\hline & Moderately & 57 & 19.0 & \\
\hline & Much & 58 & 19.3 & \\
\hline & Very much & 35 & 11.7 & \\
\hline
\end{tabular}


Table 5: (Contd...)

\begin{tabular}{llrrr}
\hline \multirow{2}{*}{ Anxiety over } & \multicolumn{3}{c}{$(N=300)$} \\
\cline { 2 - 5 } Health of the fetus & Response & \multicolumn{1}{c}{$N$} & $\%$ & Chi-square tests \\
\hline & Very little & 36 & 12.0 & $p$-value $=0.05$ \\
& Little & 29 & 9.7 & \\
Moderately & 41 & 13.7 & \\
Much & 77 & 25.7 & \\
& Very much & 117 & 39.0 & \\
& Very little & 50 & 16.7 & $p$-value $=0.05$ \\
& Little & 49 & 16.3 & \\
& Moderately & 65 & 21.7 & \\
& Much & 60 & 20.0 & \\
& Very much & 76 & 25.3 & \\
\hline
\end{tabular}

assessment of thoughts of self-harm. ${ }^{11}$ These facts are worth to be addressed in the preventive mental health strategies.

This study highlights the importance of screening for a mental health issue in pregnant and postpartum women with effective and feasible tools like EPDS. ${ }^{29}$ The women who scored greater than 13 on EPDS and who were in isolation have been supported by the oneto-one peer support and explained about the cognitive behavioral therapy $(\mathrm{CBT}),{ }^{30}$ and also virtual consultations with the psychiatrist were offered to them. These women were expressive about their thoughts in personal counseling rather than on virtual platforms. However, these women felt reluctant to consult the psychiatrist due to the stigma of mental health problems in Indian sociocultural background. ${ }^{31}$

The COVID-19 status of the women did not make any significant difference in the occurrence of depression, and anxiety focuses on the fact that the pandemic has overall affection of mental wellbeing of the pregnant population over certain aspects related to pregnancy care and fetal health.

Depression and anxiety in antenatal and postnatal women represent the tip of the icebergs. In India, the awareness of perinatal mental well-being, breaking the barrier to seek support needs to be dealt with further in further psychological interventional studies. Implementing a culturally inclined perinatal mental health education model is the need of the hour during this pandemic.

\section{Conclusion}

This study emphasizes that COVID-19 pandemic has impacted the mental well-being of the pregnant population in terms of depression and anxiety irrespective of the affection with COVID-19. Peripartum screening for mental health issues is essential, especially during the pandemic. Preventive perinatal mental health strategies during the pandemic should be the focused element of the antenatal and postnatal care bundle. The support for women with mental health problems during the pandemic by feasible means like Web-based consultations and telephonic conversations with peers should be promoted.

\section{Strengths of the Study}

This study is one of the initial studies on perinatal mental health issues in the COVID-19 pandemic done in India.

\section{Limitations of the Study}

Due to the restrictions in containment areas, in person psychiatric consultation was not available.

\section{Acknowledgments}

The authors would like to thank Dr Zenab Tambawala for her valuable inputs in statistical analysis, Dr Aiswarya Kadrekar \& paramedical team of our hospital \& Ms Ojas Kale for their help.

\section{References}

1. Wang C, Horby PW, Hayden FG, et al. A novel coronavirus outbreak of global health concern. Lancet 2020;395(10223):470-473. DOI: 10.1016/ S0140-6736(20)30185-9.

2. Guardino $C$, Schetter $C D$. Understanding pregnancy anxiety: concepts, correlates and consequences. Zero Three 2014;34(4):12-21. eric.ed.gov/id =EJ1125704.

3. National Institute for Health and Care Excellence. Antenatal and postnatal mental health: clinical management and service guidance (CG192). NICE; 2014.

4. Upadhyay RP, Chowdhury R, Salehi A, et al. Postpartum depression in India: a systematic review and meta-analysis. Bull World Health Organ 2017;95(10):706-717C. DOI: 10.2471/BLT.17.192237.

5. Field T. Postpartum depression effects on early interactions, parenting, and safety practices: a review. Infant Behav Dev 2010;33(1):1-6. DOI: 10.1016/j.infbeh.2009.10.005.

6. Surkan PJ, Kennedy CE, Hurley KM, et al. Maternal depression and early childhood growth in developing countries: systematic review and meta-analysis. Bull World Health Organ 2011;89(8):608-615D. DOI: 10.2471/BLT.11.088187.

7. Sohr-Preston SL, Scaramella LV. Implications of timing of maternal depressive symptoms for early cognitive and language development. Clin Child Fam Psychol Rev 2006;9(1):65-83. DOI: 10.1007/s10567-0060004-2.

8. Dwenda G. The effectiveness of various postpartum depression treatments and the impact of antidepressant drugs on nursing infants. J Am Board Fam Med 2003;16(5):372-382. DOI: 10.3122/ jabfm.16.5.372.

9. Dennis $\mathrm{CL}$, Falah-Hassani K, Shiri R. Prevalence of antenatal and postnatal anxiety: systematic review and meta-analysis. $\mathrm{Br} J$ Psychiatry 2017;210(5):315-323. DOI: 10.1192/bjp.bp.116.187179.

10. Ghebreyesus TA. Addressing mental health needs: an integral part of COVID-19 response. World Psychiatry 2020;19(2):129-130. DOI: 10.1002/wps.20768.

11. Cox JL, Holden JM, Sagovsky R. Detection of postnatal depression: development of the 10-item Edinburgh Postnatal Depression Scale. Br J Psychiatry 1987;150:782-786. DOI: 10.1192/bjp.150.6.782.

12. Murray D, Cox JL. Screening for depression during pregnancy with the Edinburgh Depression Scale (EDDS). J Reprod Infant Psychol 1990;8(2):99-107. DOI: 10.1080/02646839008403615.

13. Khanlari S, Am BB, Ogbo FA, et al. Re-examination of perinatal mental health policy frameworks for women signaling distress on the Edinburgh Postnatal Depression Scale (EPDS) completed during 
their antenatal booking-in consultation: a call for population health intervention. BMC Pregnancy Childbirth 2019;19(1):221. DOI: 10.1186/ s12884-019-2378-4.

14. Taubman-Ben-Ari O, Chasson M, Sharika SA, et al. Distress and anxiety associated with COVID-19 among Jewish and Arab pregnant women in Israel. J Reprod Infant Psychol 2020;38(3):340-348. DOI: 10.1080/02646838.2020.1786037.

15. Khapre M, Dhande N, Mudey A. Validity and reliability of Marathi version of Edinburgh postnatal depression scale as a screening tool for post natal depression. NtI J Community Med 2017;8(3):116-121. www.njcmindia.org.

16. Matthey S, Fisher J, Rowe H. Using the Edinburgh postnatal depression scale to screen for anxiety disorders: conceptual and methodological considerations. J Affect Disord 2013;146(2):224-230. DOI: 10.1016/j.jad.2012.09.009.

17. Government of Maharashtra Department of Revenue and Forest, Disaster Management, Relief and Rehabilitation, Mantralaya, Mumbai- 400032 No: DMU/2020/CR. 92/DisM-I, Dated: 2nd May 2020.

18. Ceulemans M, Hompes T, Foulon V. Mental health status of pregnant and breastfeeding women during the COVID-19 pandemic: a call for action. Int J Gynecol Obstet 2020;151(1):146-147. DOI: 10.1002/ ijgo.13295.

19. Durankuş F, Aksu E. Effects of the COVID-19 pandemic on anxiety and depressive symptoms in pregnant women:a preliminary study. J Matern Fetal Neonatal Med 2020:1-7. DOI: 10.1080/14767058.2020.1763946.

20. Lebel C, MacKinnon A, Bagshawe M, et al. Elevated depression and anxiety symptoms among pregnant individuals during the COVID-19 pandemic [published correction appears in J Affect Disord 2021 Jan 15;279:377-379]. J Affect Disord 2020;277:5-13. DOI: 10.1016/j.jad.2020.07.126.

21. Ceulemans M, Foulon V, Ngo E, et al. Mental health status of pregnant and breastfeeding women during the COVID-19 pandemic: a multinational cross-sectional study. Acta Obstet Gynecol Scand 2021. DOI: 10.1111/aogs.14092.
22. Ng J, Sham A, Tang PL, et al. SARS: pregnant women's fears and perceptions. Br J Midwifery 2004;12(11):698-702. DOI: 10.12968/ bjom.2004.12.11.16710.

23. Jiang $H$, Jin L, Qian X, et al. Maternal mental health status and approaches for accessing antenatal care information during the COVID-19 epidemic in China: cross-sectional study. J Med Internet Res 2021;23(1):e18722. DOI: 10.2196/18722.

24. Antenatal care for uncomplicated pregnancies Clinical guideline [CG62] 26/03/2008, last updated February 2019.

25. Liu X, Chen M, Wang Y, et al. Prenatal anxiety and obstetric decisions among pregnant women in Wuhan and Chongqing during the COVID-19 outbreak: a cross-sectional study. BJOG 2020;127(10):12291240. DOI: $10.1111 / 1471-0528.16381$

26. Nelson AM. Transition to motherhood. J Obstet Gynecol Neonatal Nurs 2003;32(4):465-477. DOI: 10.1177/0884217503255199. PMID 12903696.

27. Schwank SE, Chung HF, Hsu M, et al. Mental health of Urban Mothers (MUM) study: a multicentre randomised controlled trial, study protocol. BMJ Open 2020;10(11):e041133. DOI: 10.1136/bmjopen2020-041133.

28. Ravaldi C, Wilson A, Ricca V, et al. Pregnant women voice their concerns and birth expectations during the COVID-19 pandemic in Italy. Women Birth 2020:S1871-5192(20)30280-8. DOI: 10.1016/j. wombi.2020.07.002. PMID: 32684343; PMCID: PMC7357495.

29. Wickberg B, Bendix M, Wetterholm MB, et al. Perinatal mental health around the world: priorities for research and service development in Sweden. BJPsych Int 2019;17(4):87-91. DOI: 10.1192/bji.2020.15.

30. Lau Y, Htun TP, Wong SN, et al. Therapist-supported internet-based cognitive behavior therapy for stress, anxiety, and depressive symptoms among postpartum women: a systematic review and metaanalysis. J Med Internet Res 2017;19(4):e138. DOI: 10.2196/jmir.6712.

31. Thorsteinsson EB, Loi NM, Farr K. Changes in stigma and helpseeking in relation to postpartum depression: non-clinical parenting intervention sample. Peer J 2018;6:e5893. DOI: 10.7717/peerj.5893. PMID: 30425892; PMCID: PMC6230434. 